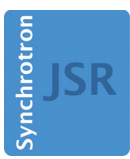

JOURNAL OF SYNCHROTRON RADIATION

ISSN 1600-5775

Received 28 June 2016

Accepted 28 June 2016

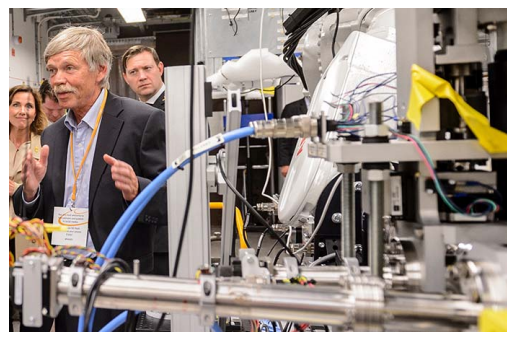

(C) 2016 International Union of Crystallography

\section{Current events}

\section{Inauguration of MAX IV, Lund, Sweden}

On 21 June 2016, summer solstice, MAX IV Laboratory was formally inaugurated by the Swedish Prime Minister Stefan Löfven in the presence of His Majesty Carl XVI Gustaf and 500 Swedish and international guests. On the day preceding the inauguration, the symposium 'Science day - the synchrotron we built for you' was held for the facility's future users.

The $3 \mathrm{GeV}$ MAX IV project initiates a new era of storage-ring light-source design - a fourth-generation facility based on a multibend achromat lattice providing extremely high brightness [see special issue on Diffraction-Limited Storage Rings and New Science Opportunities in the Journal of Synchrotron Radiation (Volume 21, Part 5, September 2014 issue)]. Over 2000 international researchers will use the facility each year. So far, investment in the facility amounts to EUR 470 million, the biggest ever investment in national research infrastructure in Sweden.

'In terms of Swedish and international research, this is truly a major event and a good example of how a small country like Sweden can pursue trendsetting projects that create an international impact. Looking ahead, MAX IV together with ESS [the European Spallation Source] will provide a unique and first-class research environment which will benefit research and innovation', said Helene Hellmark Knutsson, Swedish Minister for Higher Education and Research.

'MAX IV is the result of decades of research and innovative ideas, and it is immensely satisfying that we have reached the stage where we can inaugurate the facility. The financiers have shown great trust in us and we have to live up to that. There are great hopes both in the research community and the business sector that we will deliver results that the world has never seen before. We have an exciting period ahead of us, establishing an operation that attracts the business sector and researchers to collaborate on making

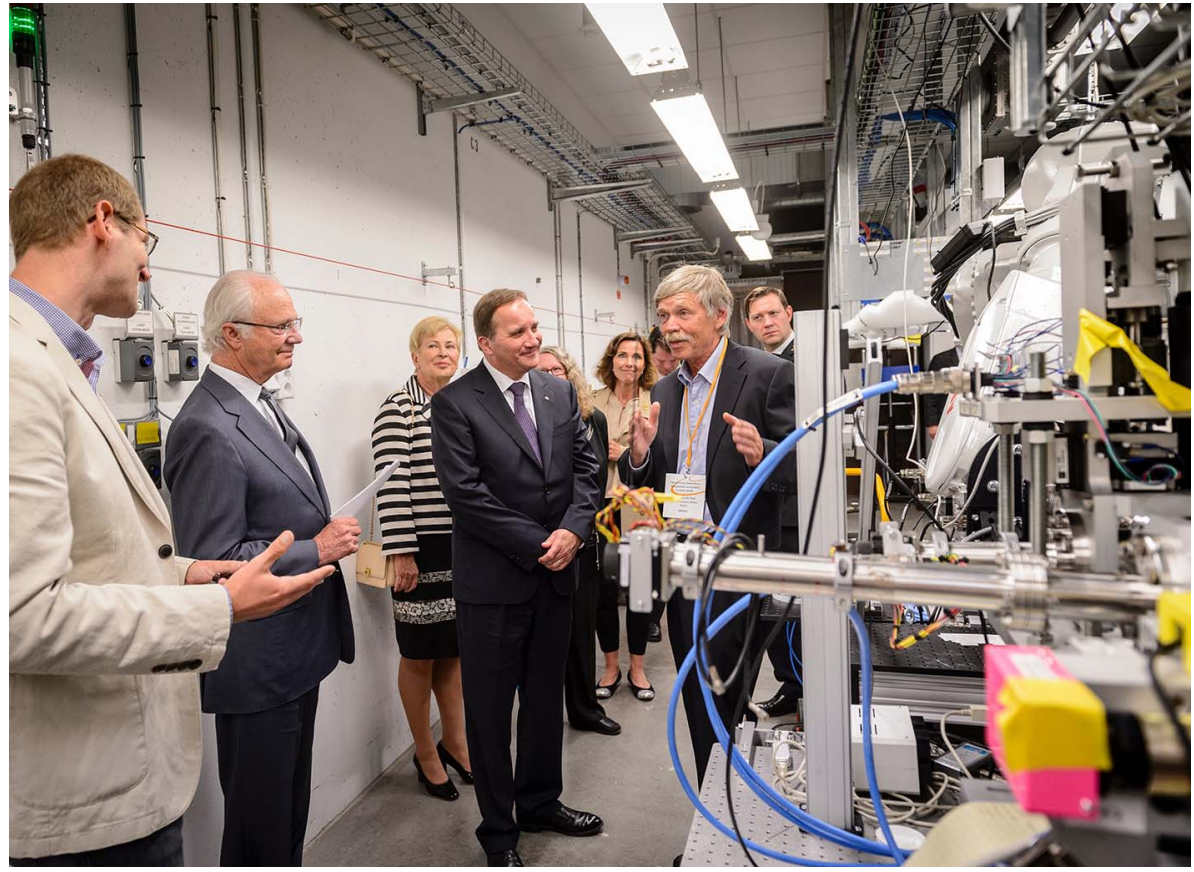

The machine director of MAX IV, Mikael Eriksson, explaining the inner workings of the facility to King Carl XVI Gustaf of Sweden, the Swedish Prime Minister Stefan Löfven, and other prominent guests of the inauguration ceremony. 
new groundbreaking discoveries', said Christoph Quitmann, Director of MAX IV.

The special magnetic technology required for the multibend achromat lattice has been developed on-site. Several other facilities around the world are now implementing the technology pioneered at MAX IV. Work on the MAX IV site outside Lund in southern Sweden started in 2010 and construction was completed in 2015. There has been a series of trials since then to test the technology. In May 2016 it was confirmed that the new technology works and the first light was delivered to the first beamlines.

At present three beamlines have seen light all the way to the detectors: (i) BioMAX (macromolecular crystallography),

(ii) NanoMAX (hard X-ray nanofocus),

(iii) FemtoMAX (generation of short pulses).

A call is out for first commissioning experiments on these and two more beamlines. In total, 14 beamlines are funded and in various stages of design and construction. Eight of them shall be ready for commissioning experiments in the summer of 2017. Soon the last missing piece of the accelerator, the transfer line to the $1.5 \mathrm{GeV}$ ring, will be installed, after which this ring will be committed. A similar $1.5 \mathrm{GeV}$ ring has been realized at the Jagiellonian University in Krakow, Poland, where it is already delivering light. 